\title{
The Child Is Capable: Anishinaabe Pedagogy of Land and Community
}

\author{
Sharla Mskokii Peltier* \\ Faculty of Education, Department of Elementary Education, University of Alberta, Edmonton, AB, Canada
}

Situated within a post-Truth and Reconciliation Commission Canadian context, educators are seeking Wisdom to create space in schools for Indigenous Knowledges, perspectives, languages, and histories. An Anishinaabe scholar invites readers to make meaningful connections to knowledge from experience that centers the child within the context of an Anishinaabe summer harvest camp, a competition powwow, and a smokehouse. The storyteller takes an inward turn, exploring features of the communal learning process conducive to the learning spirit, self-evaluation, and participation in learning and teaching that matches one's readiness and skill. The story is powerful for connecting the heart and mind, stimulating receptivity to assessment-making opportunities for teachers that are relevant to Indigenous student community teaching-learning traditions. True to the storytelling method, the stories here are meant to stimulate remembering, reflection, and a process of deep knowing. The author invites educators to think with the stories for inspiration toward personal possibilities of praxis. Positive educational transformation is set

OPEN ACCESS

Edited by:

Shaun Murphy,

University of Saskatchewan, Canada

Reviewed by:

Derek Andrew Hutchinson,

University of Kansas, United States

Emma Quiles-Fernández,

University of Barcelona, Spain

*Correspondence:

Sharla Mskokii Peltier

sharla.peltier@ualberta.ca

Specialty section: This article was submitted to

Teacher Education, a section of the journal

Frontiers in Education

Received: 31 March 2021

Accepted: 16 July 2021

Published: 31 August 2021

Citation:

Peltier SM (2021) The Child Is Capable: Anishinaabe Pedagogy of Land and Community.

Front. Educ. 6:689445. doi: 10.3389/feduc.2021.689445 into motion as teachers connect with Indigenous peoples to honor the diversity of children, co-create a relational curriculum inclusive of family and community to embrace Indigenous Knowledge that comes from the Land, and create space to generate and transmit new knowledge through story.

Keywords: indigenous pedagogy, relational curriculum, assessment, indigenous community, indigenous education, assessment, culturally responsive, Anishinaabe

\section{INTRODUCTION}

This article promotes understanding of Indigenous Knowledge processes, pedagogies, and ways of Being to disrupt educational inequities and inform assessments complementing the Indigenous child's language and community contexts. Teacher assessment of student learning aligns with Western-European epistemologies of schooling that perpetuate the sociocultural mismatch between many Indigenous children's homes and schools. The centering of Western thought and language reflects that Indigenous learners are perceived through a deficit lens. A process of decolonization in the Canadian post-TRC context moves beyond apologies for the past with complacency in the present, and the pluralist agenda of multiculturalism, to make significant contributions to educational transformation with validation of Indigenous Knowledge, ideology, and learning spaces inclusive of Indigenous traditions of teaching and learning. This article and the stories shared engage educators in a journey of learning and unlearning. Learning about and growing understanding of Indigenous Knowledge as a construct brings focus to appropriate assessment based on Indigenous pedagogical processes and ways of knowing. Unlearning what counts as knowledge in the classroom opens windows of possibility for different kinds of knowledge and assessments that are inclusive of the Indigenous student. Since patterns of colonial violence can be found on every 
continent, it is imperative that decolonizing education be an Indigenous responsibility and be placed at the forefront of education. This article may lead Indigenous and nonIndigenous educators to consider the value of an Indigenous assessment paradigm for a relational learning environment.

The stories presented here are based on my lived experiences and are meant to illuminate Indigenous community contexts for teaching-learning, shedding light on the gifts, skills, and capabilities of the child. Assessment in school classrooms provides a narrow glimpse of learning skills and processes at a particular point in the child's academic learning. Teachers cognizant of the bigger picture of what the Indigenous child brings to the classroom are positioned to make learning and assessment culturally relevant and appropriate to the local context.

Stories shared in this article are about Anishinaabek children immersed in family and community activities to illustrate Indigenous teaching-learning traditions and stimulate queries around classroom learning assessments. Indigenous Knowledge processes and teaching-learning contexts grounded in Lands and Waters and community relationships are brought to the forefront through story, informing educators' appreciation of different kinds of knowledge and family and community contexts where Indigenous children demonstrate gifts, have agency as learners, and are capable. In line with Indigenous story tradition cultural practices, the stories in this article are "given away" with the intention that the details are pivotal for educational practitioners and policymakers to generalize to their world. The power of story for decolonial educational transformation is evident in the provocation of things for the reader to notice, reflect upon, and do. The reader is invited to think with the stories and to be inspired toward personal possibilities of praxis for educational transformation by returning to reflect on the stories after reading the article.

This article is inspired by the Indigenous scholarship of resurgent epistemological and ontological ways alongside the critical examination of the colonial hegemony of schools that marginalizes Indigenous students. The article is intended for educators, teacher educators, policymakers, educational administrators, and educational researchers interested in culturally responsive Indigenous learning assessment. The honoring of story, relationships, and authenticity in academia is brought forth in the writing for readers to think with the stories to find inspiration toward personal possibilities of praxis for educational transformation. Positive educational transformation is set into motion as teachers connect with Indigenous peoples to honor the diversity of children, co-create a relational curriculum inclusive of family and community to embrace Indigenous Knowledge that comes from the Land, and create space to generate and transmit new knowledge through story.

\section{The Purpose of This Article Is Threefold}

1. To inform the educator's journey toward understanding and valuing Indigenous culturally responsive teaching-learningassessment.

2. To illustrate the Anishinaabe child's engagement with Indigenous Knowledge as a lived, communal process of coming to know at a deep level and family-community perspectives that the child has agency and innate gifts and capability in learning.

3. To inspire educators to take action in ways that honor relationality and reconciliatory educational transformation by building relationships with Indigenous families and communities, so that teacher observations and experiential stories inform praxis for Indigenous student success.

This article begins with a story and photo (Figure 1) taken on a hot July afternoon on the north-eastern shore of Lake Huron to illustrate the foundational principle within an Indigenous teacher-learner paradigm that the child is viewed as capable. The child as a deficit is a foreign/colonial and harmful lens.

Anishinaabek ${ }^{1}$ were camped for 1 week of family cultural experiences harvesting, preparing, and storing local foods. A group of adults were gathered in a shady area preparing dried cakes from a mixture of fish, berries, maple sugar, and fat. Children were within sight at the beach, where they swam and played in the frigid water. One of the camp leaders was pounding dried fish. He used a wooden stump and a 10-pound stone to pulverize the dried fish inside a pillowcase. A seven-year-old boy, slender and bronzed from the summer sun came close to observe for a minute and then he asked, "Can I do it?" The man handed the stone to the boy and held the pillowcase in place on the stump. From his place on the ground, he looked up at the boy with a huge smile. The boy balanced the heavy stone on his shoulder for a moment and with both hands, guided the stone with precision to hit the target. "Whump!" A spontaneous cheer from the adults rose up to acknowledge the child's skill. The boy's face lit up. Within a few seconds, he turned and ran back to the beach.

\section{MAKING AN INDIGENOUS PARADIGM VISIBLE}

\section{Indigenous Knowledge}

A good starting place for motivating educators to take on the work of bringing Indigenous culturally grounded assessment into their praxis begins with appreciating Indigenous Knowledge and relational epistemological principles, understanding and valuing the Indigenous ways of teaching-learning and assessment. Scholars from diverse academic and cultural perspectives have created space for a progressive epistemological position in academia, which holds that there are different ways of knowing and conceptualizing reality. Indigenous peoples come to know through language, songs, stories, ceremonies, observations, and dreams, and the validity of Indigenous Knowledges in the academy is gaining respect.

${ }^{1}$ The term Anishinaabek refers to Anishinaabemowin-speaking peoples and includes the Algonquin, Chippewa, Delaware, Mississauga, Odawa, Ojibway, and Potawatomi of the Great Lakes Region of North America. The term Indigenous in this article refers to the first peoples that occupied North America and, more specifically, Canada-unique in their own cultures-but common in their experiences of colonialism and understanding the world. 
Indigenous Knowledge is a lived process situated within a context of relationships. Indigenous scholars bring focus to the vastness of relationality and situate Indigenous Knowledge within systems of interdisciplinarity and cosmology. Mi'kmaq scholar and educator Battiste, in 2020, (Battiste, 2010) described "the learning spirit” as an animated process and experience. Cree philosopher Ermine (1995) has examined Indigenous Knowledge as an interaction of life experience, relational collectivity, and inner knowing, for example, “(e)xperience is knowledge” (p. 104).

The Anishinabek and other Indigenous nations, in what is now called Canada, transmit Indigenous Knowledge through the oral tradition. Stories and Teachings have been passed on orally since time immemorial. The philosophy that knowledge comes from the Earth ${ }^{2}$ is exemplified by "a broad sense of knowledge with a specific place and the pedagogy contained within the stories that were conceived within that place" (Kulneik et al., 2010, 19). As Indigenous peoples, we originated on Turtle Island/ North America and we have been gifted with original instructions to live a relational way of life that is in balance and in harmony with the Creation. Indigenous Knowledge is a way of Being, knowing, and doing over one's lifelong process of observing, listening, engaging in life activities, and developing skills modeled by family and community members. It means developing our gifts and sharing them to support our families and communities.

The relationship of memory and story within Indigenous educational processes is different from Western conceptualizations of knowledge and rote learning. Elder stories about experiences and observations of the natural environment represent knowledge through stories passed from generation to generation. The maintenance of mutual balance and harmony in all aspects of Creation is supported by ways of acquiring knowledge and codes of behavior through oral tradition and storytelling. Cultural-social ways of Being in an Indigenous paradigm underscore the value of knowing who we are and where we come from. A person values and listens to Elders' stories, creating consciousness of the past and informing worldviews, responsibilities, and commitments. Present time and future life considerations flow from personal experiences and knowing the collective memories. A person's ability to make good decisions is a reflexive process stimulated from careful listening and respect for Elders' stories and insight into personal lived experiences. There is a moral duty to remember in this way. Oral history tradition represents Indigenous Knowledge in a non-linear way, based on experience, reflection, and re-telling ${ }^{3}$. The storyteller imparts their own life and experience into the telling of stories and the listeners filter the story being told through their own experience and reflective thinking and make it relevant to their own life. The oral tradition sustains culture and is upheld by the responsibility to share stories in the community. The culturally embedded role of the storyteller is to make sense of his/her own life story concomitant with the collective memories of the people and to share the reinterpretation.
The socio-cultural-linguistic relationality of an Indigenous paradigm forms the context for learner engagement in a holistic process of embodying new knowledge. Indigenous pedagogy is a lived experience where intuition and the inner journey of reflection inform a learner's process of coming to know deeply. Learning about the inner process of balancing the heart, mind, intuition, and body through being in the moment and journeying to the inner space of reflection and self-knowing are fundamental to exuding positive perspectives outwards to relationships with others and for the understanding of and appreciation for Indigenous perspectives. The non-linear, cyclical process and non-compartmentalized nature of Indigenous Knowledge mean that the learner engages in learning over their life-path journey with different experiences stimulating a variety of entry points at different times for deeper learning.

The learning journey is guided by family and community in relationship with Land and the child's gifts and skills are made visible through communal and ceremonial processes. Learning begins in the womb, where the child is central within a relational way of Being. Cultural ways of honoring the child and supporting their early development are significant to grounding them to Place during their early years. These culture-based early child development practices were almost extinguished due to colonial policies and racist interference but are being revitalized in Indigenous families and communities today. An Indigenous child's early learning is primarily guided by the parents, grandparents, and family members. The kinship structure of the Anishinaabe family is extensive beyond blood relatives. Negwaadodem refers to the whole clan of family and community kinship inclusive of ancestors. Kinship terms of endearment are modeled and the individual shows respect for those who teach and care for them by calling them, "Niitaawis/ cousin," "Nooshenh/auntie," "Nizhishenh/uncle," "Nookmis/ grandmother," and "Mishoomis/grandfather." Over the course of the life-path journey, Indigenous Knowledge keepers, language keepers, grandmothers, and grandfathers provide guidance and support as the individual engages in learning toward the acquisition of Nibwaakaawin/Wisdom.

\section{Language}

The incorporation of Anishinaabemowin ${ }^{4}$ (Ojibway language) conveys worldview perspectives and exemplifies the Indigenous paradigm and ways of knowing. In my academic journey over the past 10 years, I have been dedicated to examining Indigenous educational philosophy and teaching-learning contexts. My learning and writing processes have been enriched by being alongside Odawa Elder, Stanley Peltier (my husband), Language Keeper. As a language learner, our discussions about the contexts of education being examined create opportunities for meaningful connections that Anishinaabemowin provides. Over the years, my stories and written work incorporate
${ }^{2}$ Earth and other words that are typically not capitalized appear in this article with a capital letter to denote an Indigenous voice and Indigenous perspective.

${ }^{3}$ Willie Ermine, 1995, 101-112.
${ }^{4}$ Anishinaabemowin refers to the Aboriginal language and language dialects of the Anishinaabek. 
Anishinaabemowin, more and more, to be centered on conceptions of Anishinaabe relationality and worldview.

\section{Indigenous Story Method}

The Indigenous story method (Wilde, 2003; Kovach, 2009) is fundamental to an Indigenous Knowledge paradigm where knowledge is experience and knowledge transfer occurs through story. As an Anishinaabe Kwe (woman), what I bring forward is not knowledge from a neutral or objective positionality but knowledge that comes from the Land by living in a good and relational way with Lands and Waters. In this article, I share stories from observations, queries, and reflections from being alongside Anishinaabe children immersed in family and community activities on the Lands and Waters.

I situate myself as a teacher-learner and offer stories to illustrate what Indigenous Knowledge is and how I teach and learn. Lived experiences and engagement in listening, observing, and engaging in family and community processes and repeating cycles of reflection on lived experiences and relationships motivate me to take notice, question, and come to know more deeply. Immersion in the storytelling tradition means that I value and share personal experience stories to connect with others and contribute to the creation of new knowledge.

Indigenous Knowledge comes from the Land and each of us is situated in a specific place. In my place of origin, I am known as Mskokii Kwe or Red Earth Woman and I am a member of the Loon Clan. I was raised by my parents and paternal grandmother. My father, Ivan, grew up with his mother, Emma Douglas, in Mnjikaning. My mother, Peggy, grew up with her parents, Mary Moness and Joseph Monette, in Golden Lake First Nation. My identity and selfdevelopment are grounded in Odenang or where the heart is-my home and community of origin-Mnjikaning. Mnjikaning is a place in the Great Lakes area of Ontario where two freshwater lakes, Lake Simcoe and Lake Couchiching, meet and where Indigenous people have gathered to fish and trade for 5,500 years. I grew up on the eastern shore of Lake Couchiching and my father taught me how to live with the lake in a respectful way so that we could harvest fish, eat, and make a living selling bait and guiding. The lake was our life. Odenang is the foundation of who I am and who I am becoming.

Indigenous philosophy of life is understood through human and more-than-human interconnectivity. My family and community have a broad kinship system. I am in a reciprocal relationship with the Creation-the two-legged, the four-legged, the winged, and the finned ones, and those that hop and crawl. My family relationships extend beyond blood relations to include sisters, brothers, aunties, uncles, grandmothers, and grandfathers in places on Turtle Island and beyond. The term Weh refers to a sensibility of connection that has gradually developed from a process of heart-knowledge interacting with mind-knowledge. I conceptualize my connection not only with family and community but outward to society, Aki/Land, and the Universe.

In my doctoral work, I describe relationality with: the Four Directions; the level of Aki/Land; the Sky World; and what is underneath or our Ancestry. The following metaphor reveals deep relational knowing of Lands and Waters, "I am the water. I am the land. What I do to the water I do to myself. What I do to the land I do to myself."

\section{Holistic Indigenous Pedagogy}

An Indigenous pedagogy model from my doctoral research (Peltier, 2017) is applied here to illustrate Indigenous Knowledge as a learning process of embodied/wholistic engagement in listening and thinking, intuitive reflecting and visioning, experiencing and doing, and relating and feeling. Ways of knowing within an Indigenous Knowledge paradigm and pedagogical process means negotiating my physical world and the unseen and more-than-human reality. Acquisition of Indigenous Knowledge is not a linear progression of acquiring skills, processes, and subject content. Indigenous Knowledge means different things depending on what the listener knows, understands, and experiences and listener interpretation is governed by what they need to focus on. The learning process is self-actualized within a sociocultural context of being a responsible learner and passing on stories.

\section{The Problem}

The current assessment practices employed in Canadian schools, which are intended to evaluate students' cognitive understanding of Western knowledge systems, are inadequate for Indigenous learners. Indigenous Knowledge is a lifelong learning process of collectivity rather than a sequential process where the individual acquires specific skills and masters subject matter. Educational theorists identify a problem with specific subject areas in school that compartmentalize education into discrete subject areas. This educational context is a disservice to students when opportunities for understanding the connections between language, location and environment and appreciation of interconnectivity and interdependence with the Earth and nature are ignored. Battiste (1998) has coined the term "cognitive imperialism" to describe the process by which Western thought and language are constructed as superior and Indigenous Knowledge and language as disposable. Assessment beyond the cognitive understanding of Western knowledge systems requires the adoption of alternative assessment practices.

\section{Critical Discourse}

This article is motivated by a critical examination of attitudes and professional practices based on Western-European epistemologies that perpetuate the sociocultural mismatch between many Indigenous children's homes and schools. Indigenous learners are often seen from a deficit lens in school, while in their family and community contexts, they are gifted, have agency as learners, and are capable.

Critical discourse ensures the integrity of research and mobilization toward locally developed contextualized assessment practices across theories of Indigenous Knowledge, epistemology, and relational, deep ways of coming to know. Western ways of knowing are closely tied to viewing the world objectively with scientific and rational thought and logic. Assessments in school are designed with Western cultures, expectations, and conceptions of what intelligence is and a holistic range of intelligence is excluded from the generally accepted understanding. Dumont (2006) has described Indigenous intelligence as the intelligence of the mind, the intelligence of the heart, the intelligence of the body, the 
intelligence of the soul, and the intelligence of the spirit (p. 4). An essential principle of an Indigenous paradigm is the perception of the big picture or " $360^{\circ}$ seeing" (Dumont, 1976) for the consciousness of all contextual interconnections. This Wholism is an essential principle of Indigenous epistemology.

Our work as educators is crucial to forge new relationships and heal the negative and hurtful relationship between Indigenous peoples and schooling. A culturally responsive assessment paradigm provides an environment and educational philosophy that leads to Aboriginal student success. Sense of cultural identity and belonging and engagement in supportive relationships are strongly associated with school success of particular relevance for Aboriginal student engagement in school. As new understandings facilitate the resolution of historical trauma and strengthening of healthy relationships, we can collectively promote biophilia (the love of nature) and Indigenous Knowledge and pedagogy. Valuing Indigenous contexts of teaching-learning assessment is motivational for teachers to initiate good relationships with Indigenous families and communities. Being present, observing children's learning processes and achievements goes a long way to build culturally responsive assessment skills and strategies that inform the classroom.

Educators and teachers as researchers face challenges in collaborative relationships with Indigenous communities due to epistemological differences and professional attitudes that stem from the historical subjugation of Indigenous Knowledge. Most educators and investigators are unaware of the sociolinguistic practices and cultural background of the Indigenous student, and learning assessments do not account for what the child knows within the bigger context of family and community. The stories I share in this article offer a glimpse into what it means to experience learning and assessment from the perspective of an Indigenous consciousness. The stories illustrate a lens of seeing the child as capable from within an Indigenous learning paradigm.

\section{The Child is Capable: Case Narratives From Indigenous Community Contexts}

The following stories are presented to illustrate how knowing the bigger picture of the Indigenous child in relation to family and community can inform a teacher's journey of creating space for culturally responsive learning and assessment in the classroom. I re-tell these stories in my living of Indigenous community experience and work as an educator and scholar engaging in critical, reflective practice.

The story below is illustrated with a photo (Figure 2) taken on a hot August afternoon on Manitoulin Island, Ontario. A six-yearold Anishinaabe child engages in play while waiting patiently to be called to dance in the girls' butterfly category at a competition powwow. The following story is shared to illustrate an Indigenous family and community context where the child has agency and understands responsibility, gratitude, and sharing. The child's innate gifts that set her apart are celebrated. She exudes dignity with personal colors that accent her unique Anishinaabe name, and she moves in a beautiful, light-footed dance, in tune with the rhythmic Grandfather Drum. This six-year-old girl has been socialized to take responsibility for her regalia and to dance her very best to honor Bimaadiziwin - the good life. She has been a part of the powwow circle with her parents since before her birth and has been immersed in powwow teaching-learning processes throughout the years. This girl has already achieved status as a champion fancy dancer within what is referred to as "the powwow trail." The young girl knows that once called, she will have 2 or 3 min to enter the dance arena before the drum sounds and the singers render a competition song for her to show her stuff.

From the photo, we can appreciate the young girl's understanding and dedication to the powwow schedule. She busies herself in imaginative play and shows awesome creativity. Scripts from familiar places and activities play out as she creates figures and performs actions with the rocks and sticks. At the same time, her listening and attention to what is happening around her do not waver so that she does not miss being called to dance for the people.

This young child looks after every part of her regalia, being careful to sit on a blanket, always watchful of her beadwork and feathers so as not to lose anything. Her beautiful powwow regalia has been handmade by her aunties and the patterns, symbols, and colors reflect her unique identity and home. Some of her items are cherished gifts from supportive community members. When the powwow is over, she packs up quickly and accounts for every aspect of her regalia, intentionally placing everything neatly in her suitcase. If her moccasins are damp from dancing on the wet grass, she makes sure to avoid ruining them. The girl later removes them from the suitcase until they dry out and she responsibly packs them again. She has learned from experience that arriving at the powwow with no moccasins interferes with her chances of placing in the top three dancers within her category and being awarded a significant amount of money.

This young butterfly dancer understands good relational ways of Being that include gratitude, sharing, and accountability. She has earned a lot of cash over the years at powwows. She is happy to share with her siblings and friends at the food vendor booths, and she saves up to purchase special handmade beadwork and embellishments for her regalia from the powwow trade booths. Occasionally, she contributes gas money for travels far and wide on the powwow trail with her family.

A teacher who knows a child's engagement in Indigenous Knowledge processes and appreciates the expanse of their knowledge, skills, gifts, attitudes, and community contributions from a Wholistic lens and centers relevant assessment and inclusivity in the classroom. Teachers can create performative assessment tasks, self-assessment opportunities, and group-, family- and community-inspired inquiry projects and portfolios to highlight the relational knowledge of the child beyond the confines of subject area book knowledge.

My children are my teachers. I share a third story below about my son, Ashkidebekegiizis (Vincent), as shown in Figure 3. At age eight, he embodied Indigenous ways of knowing and a relational way of Being. His classroom teacher had no awareness of the breadth, depth, and rigor of the Indigenous Knowledge systems he could masterfully navigate alongside Lands, Waters, family, community, and the more-than-human world. 


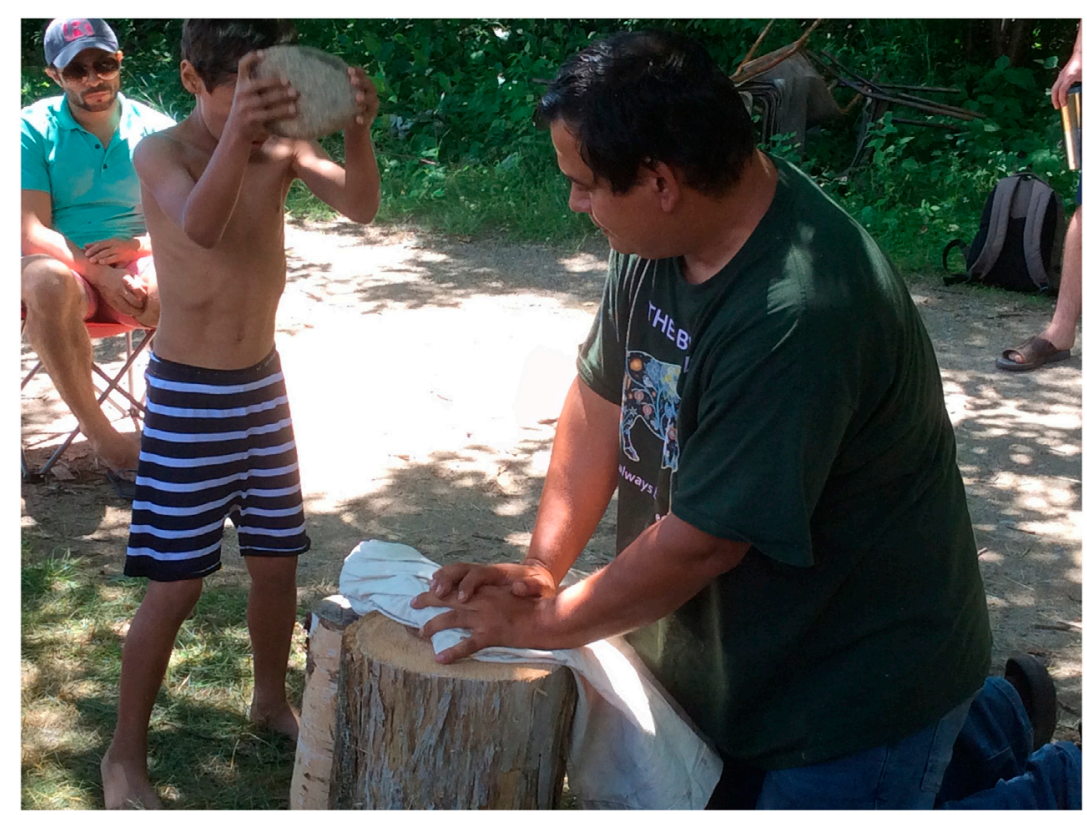

FIGURE 1 | Pounding dry fish at a food harvesting camp (photo credit: Sharla Peltier).

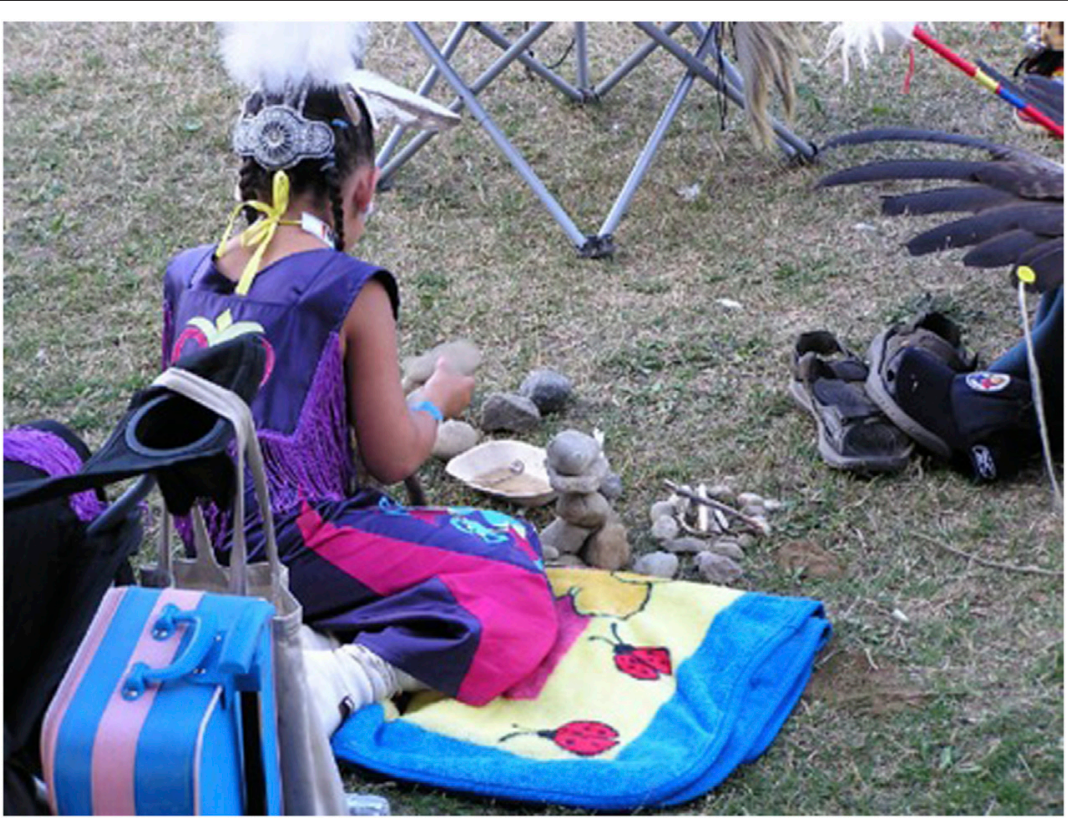

FIGURE 2 | Champion dancer waiting to be called to the powwow arena (photo credit: Sharla Peltier).

As a boy, Ashkidebekegiizis participated in the harvesting and preserving of fish with us every year, and by the age of eight, he understood his relationship to Land/Aki and the seasons, the fish, lakes, and our family. How human relationships with Place are understood and experienced ties directly to the relationships that teachers-learners have with each other. My son's land-based learning began when I carried him before he was born and it continued when he was an infant in the cradleboard where he was at the center of everything we did as a family. In his early years, Ashkidebekegiizis came to understand the relational ceremony, natural law, and ethics around fishing.

We plan before we set out; we set out with intention and focus so that we do the work of preparing ourselves, the nets, fishing rods, and boat with purpose; we acknowledge our relationships 


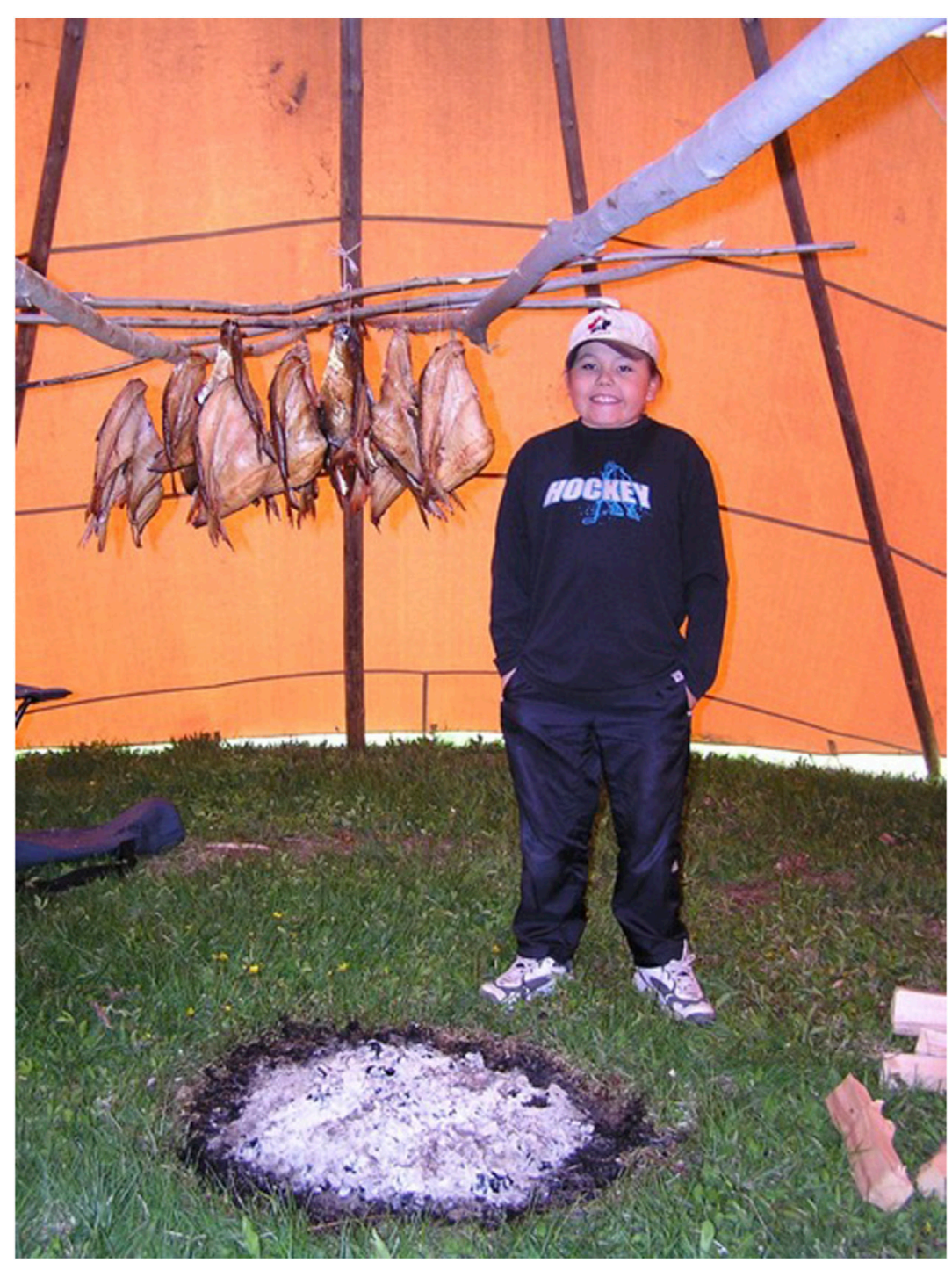

FIGURE 3 | Preserving fish in the smokehouse (photo credit: Sharla Peltier).

and interdependence with all things natural; we speak our truth to the waters and fish with Asemaa/tobacco in our left hand, closest to our heart. Nothing is taken for granted. We state our need to travel safely and obtain enough fish to feed our family today, and we acknowledge and speak our gratitude to the lake and address the winds, asking for prevailing winds that are mild for safe travel on the lake and good setting/gathering of the nets, and we speak and sing to the fish so that our harvest is bountiful to feed our family.

\section{Provocation for Reflexivity in Praxis}

In line with story tradition cultural practices, the stories in this artic;e are "given away" with the intention that the details are pivotal for educational practitioners and policymakers to generalize to their world. The power of the story for educational transformation is evident in the provocation of things for the reader to notice, reflect upon, and do.
The stories shared in this article about Anishinaabek children immersed in family and community activities, illustrate Indigenous teaching-learning traditions, and stimulate queries around classroom learning assessments. "If the classroom teachers are unaware of the children's gifts, aptitudes, skills, and achievements, how does this limit assessment of learning?" The stories can be considered to live on in the ongoing, intergenerational retelling and through the forthcoming oral tradition in families and communities passing on knowledge. Stories like these inform ways forward in the development of culturally relevant teaching-learning in school and assessments that are informed by the bigger social contexts of community and family engagements in culturelanguage revitalization. Students' sense of cultural identity and supportive relationships are strongly associated with school success of particular relevance for Aboriginal student engagement in school. 


\section{Imagining Forward}

As educators decolonize and indigenize learning spaces, valuing the expertise that the Indigenous community brings to the classroom is raised as teachers work to strengthen and sustain community ties and partnerships. Of key importance is the unique, local context of learning. As educators, professional practice is steeped in valuing the Indigenous child's gifts and linguistic, cultural, social, historical, and political experience and assuming the role of the learner in the Indigenous education context to develop understanding about the wider Indigenous paradigm of the home-school-community-nation.

"How do educators engage in the assessment of Indigenous learners in culturally responsive and respectful ways?" This remains to be seen. A myriad of recommendations are evident from the educational literature. Indigenous, Metis, and Inuit lifelong learning models were introduced in a Canadian Council on Learning report (2007) and applications to the assessment of Indigenous school-age children are evident. The key attributes of Indigenous learning should be accommodated and evaluated within Canadian schools in efforts to eliminate Eurocentric bias from schools, ensuring that Indigenous ways of knowing and being are equitably represented. For learning to be relevant to Indigenous people, it must be rooted in language and culture; experiential in nature; Wholistic; community-based; lifelong; spiritually oriented; rooted in a combination of Indigenous and Western knowledge.

Johnston and Claypool (2010) have investigated measures of learning success as identified by Indigenous peoples. The researchers presented a multi-method assessment model and posited that norm-referenced testing should be combined with other authentic forms of testing so as to accurately evaluate the redefined learning objectives as identified by the Canadian Council On Learning (2007). The work of Gardner (1983) regarding multiple intelligences is called into play to guide learning evaluation techniques that are capable of evaluating multiple forms of intelligence and ways of knowing that extend beyond what the Western world has traditionally conceptualized as valid knowledge. "Norm-referenced tests remain a valid means of testing for empirical knowledge germane to Western culture. They recommended a search for other "authentic" assessment practices to accompany norm-

\section{REFERENCES}

Battiste, M. (1998). Enabling the Autumn Seed: Toward a Decolonized Approach to Aboriginal Knowledge, Language, and Education. Can. J. Native Edu. 22, 16-28.

Battiste, M., and Henderson, J. (2000). Protecting Indigenous Knowledge and Heritage. Saskatoon, SK: Purich Publishing Ltd.

Battiste, M. (2010). Nourishing the Learning Spirit: Living Our Way to New Thinking, Educ. Assoc. Can., 50. 14-18.

Canadian Council on Learning (CCL) (2007). Redefining How success Is Measured in First Nations, Inuit and Métis Learning. Retrieved 29 June 2008 from Available at: http://www.cclcca.ca/CCL/Reports/ RedefiningSuccessInAboriginalLearning? Language $=\mathrm{EN}$.

Dumont, J. (2006). Indigenous Intelligence. Sudbury: Inaugural J.W.E. Newberry Lecture. University of Sudbury. doi:10.1201/ 9781439823552.ch8 referenced evaluations that are capable of testing for knowledge relevant to indigenous peoples and capable of accommodating indigenous teaching and learning techniques" (Claypool and Johnston, 2010, p. 127). The authors recommended developing a multi-method assessment model through the relationships with the child, parent(s), sibling(s), extended family, elders, community members, peers, teachers, administrators, and other professionals. Such an approach is relevant to the locale and assessments are developed to suit specific community contexts.

The reader is invited to return to the case narratives shared in this article. A teacher's journey of gaining appreciation and coming to know the gifts of the Indigenous child and the bigger picture of relationality, embodied learning, and cultural teaching-learning-assessment traditions with family and community informs educational praxis for culturally responsive assessment in the classroom. Initiating relationships and building a supportive network take time and commitment and observing and listening are most important. All teachers, Indigenous and non-Indigenous, do not do this work on their own.

\section{DATA AVAILABILITY STATEMENT}

The original contributions presented in the study are included in the article/Supplementary Material; further inquiries can be directed to the corresponding author.

\section{ETHICS STATEMENT}

Written informed consent was obtained from the individual(s) and legal guardian/next of kin for minor(s) for the publication of any potentially identifiable images or data included in this article.

\section{AUTHOR CONTRIBUTIONS}

The author confirms being the sole contributor to this work and has approved it for publication.

Dumont, J. (1976). “Journey to Daylight-Land: Through Ojibwa Eyes," in The First Ones: Readings in Indian/Native Studies. Editors D. Miller, C. Beal, J. Dempsey, and R. Heber (Craven, SK: Saskatchewan Indian Federated College Press), 75-80.

Ermine, W. (1995). "Aboriginal Epistemology," in First Nations Education in Canada: The circle Unfolds. Editors M. Battiste and J. Barman (Vancouver, BC: UBC Press), 101-112.

Gardner, H. (1983). Frames of Mind: The Theory of Multiple Intelligences. New York: Basic Books.

Johnston, A., and Claypool, T. (2010). Incorporating a Multi-Method Assessment Model in Schools that Serve First Nations, Inuit, and Metis Learners. Native Stud. Rev. 19 (2), 121-138.

Kovach, M. (2009). Indigenous Methodologies: Characteristics, Conversations, and story as Indigenous Methodology. U of T Press.

Kulnieks, A., Longboat, D. R., and Young, K. (2010). An Eco-Hermeneutic Approach to Learning. AlterNative: Int. J. Indigenous Peoples 6 (1), 15-24. doi:10.1177/117718011000600102 
Peltier, S. (2017). An Anishinaabe Perspective on Children's Language Learning to Inform "Seeing the Aboriginal Child". L. L. 19 (2), 4-19. doi:10.20360/ g2n95c

Truth and Reconciliation Commission of Canada (2015a). Honouring the Truth, Reconciling for the Future: Summary of the Final Report of the Truth and Reconciliation Commission of Canada. Winnipeg: The Commission. Retrieved from Available at: http://www.trc.ca/websites/.trcinstitution/File/2015/ Findings/Exec_Summary_2015_05_3 1_web_o.pdf.

Truth and Reconciliation Commission of Canada (2015b). Truth and Reconciliation Commission of Canada: Calls to Action. Winnipeg, MB: The Commission. Retrieved from Available at: http://www.trc.ca/websites/ trcinstitution/File/2015/Findings/Calls_to_Action_English2.pdf.

Wilde, K. (2003). "Storytelling as A Methodology," in Native Voices in Research. Editors Jill. Oakes, Rick. Riewe, Alison. Dubois, Alison. Edmunds, and Kimberley. Wilde (Winnipeg: University of Manitoba, Aboriginal Issues Press, 2003), 191-198.
Conflict of Interest: The author declares that the research was conducted in the absence of any commercial or financial relationships that could be construed as a potential conflict of interest.

Publisher's Note: All claims expressed in this article are solely those of the authors and do not necessarily represent those of their affiliated organizations, or those of the publisher, the editors and the reviewers. Any product that may be evaluated in this article, or claim that may be made by its manufacturer, is not guaranteed or endorsed by the publisher.

Copyright $\odot 2021$ Peltier. This is an open-access article distributed under the terms of the Creative Commons Attribution License (CC BY). The use, distribution or reproduction in other forums is permitted, provided the original author(s) and the copyright owner(s) are credited and that the original publication in this journal is cited, in accordance with accepted academic practice. No use, distribution or reproduction is permitted which does not comply with these terms. 